\title{
CULTURA DOS CUIDADOS: MULHERES NEGRAS E FORMAÇÃO DA ENFERMAGEM PROFSSIONAL BRASILEIRA
}

Paulo Fernando de Souza Campos ${ }^{1}$, Taka 0 guisso일 Genival Fernandes de Freitas ${ }^{3}$

${ }^{1}$ D outor em H istória. Pós-D outorando do Departamento de O rientação Profissional da Escola de Enfermagem da U niversidade de São Paulo EN O /EEU SP.

${ }^{2}$ Professora Titular do Departamento de O rientação Profissional da Escola de Enfermagem da Universidade de São Paulo - EN O /EEU SP.

${ }^{3}$ Professor D outor do Departamento de O rientação Profissional da Escola de Enfermagem da Universidade de São Paulo - EN O/EEU SP.

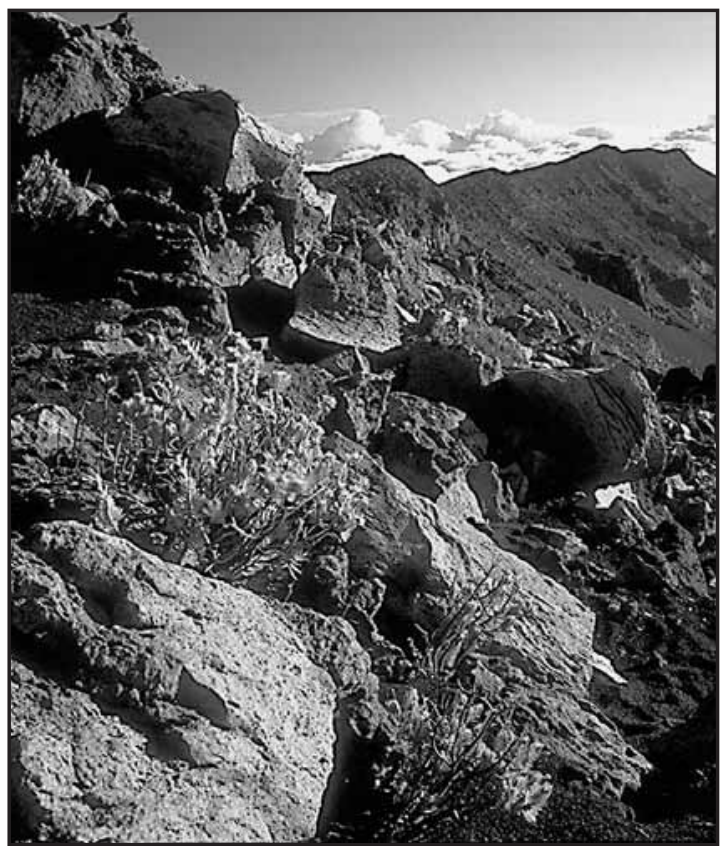

CULTURA DE LOS CUIDADOS: MUJERES NEGRAS Y LA FORMACIÓN DE LA PROFESIONALIZACIÓN DE LA ENFERMERÍA BRASILEÑA

\section{RESUMEN:}

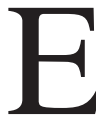

ste estudio pretende analizar el proceso de exclusión de mujeres negras de los orígenes de la enfermería profesional brasileña. Embasado en las proposiciones de la antropología de los cuidados, el texto demuestra que mujeres negras ejercían el cuidado antes de la profesionali- zación de la enfermería. El resultado de este proceso ha creado una identidad para la enfermería brasileña caracterizada esencialmente por la mujer blanca, hija de las élites. La reflexión nos permite suponer que las representaciones del negro reiteraran estereotipos que dificultaban la inclusión de negras en la moderna enfermería, en la medida en que la visibilidad del ha proyectado las mujeres negras como moralmente descalificadas, caracterizándolas como impropias para ejercieren el arte y la ciencia del cuidado.

Descriptores: Historia de la enfermería, Mujeres Negras, Identidad Profesional.

\section{CULTURE OF CARING: BLACK WOMEN SHAPING THE BRAZILIAN PROFESSIO- NAL NURSING}

\section{ABSTRACT:}

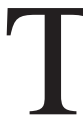

his paper intends to analyze the exclusion of black women process from the origins of

the Brazilian professional nursing. Based on the proposition of the anthropology of care, this study shows that black women cared sick people before the nursing professionalization in Brazil. Results of this process have created a professional identity for Brazilian nursing essentially characterized by white woman, daughter of elite. A reflection allows us to suppose that black representations in Brazil have reiterated stereotypes that has prevented from inclusion of blacks into modern nursing, while the black representation within Brazil has projected black women as morally disquali- 
fied, characterizing them as inappropriate for practicing the art and science of caring.

Descriptors: Nursing History, Black women, Professional identity.

\section{RESUMO:}

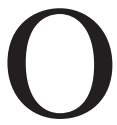
artigo pretende analisar o processo de exclusão de mulheres negras das origens da enfermagem profissional brasileira. Fundado nas proposições da antropologia dos cuidados, o artigo demonstra que mulheres negras exerciam o cuidado junto aos doentes antes da profissionalização da enfermagem no Brasil. O resultado deste processo criou uma identidade profissional à enfermagem brasileira caracterizada essencialmente pela mulher branca filha das elites. A reflexão permite-nos supor que as representações do negro reiteraram estereótipos que coibiam a inclusão de mulheres negras na enfermagem moderna, na medida em que seus significados projetavam as mulheres negras como moralmente desqualificadas, caracterizando-as como impróprias para exercerem a arte e a ciência do cuidado.

Descritores: História da Enfermagem Mulheres Negras - Identidade Profissional

\section{INTRODUÇÃO}

A passagem do século XIX para o século XX marca o período em que a historiografia tradicional, resultado de narrativas oficiais, que exaltavam a realização dos detentores do poder, deixou de ser o paradigma da escrita da história ou sua única face. Interessados em uma nova possibilidade de interpretação do passado, novos historiadores buscavam em acontecimentos menos visíveis outras possibilidades de reconhecimento histórico.

Contrária à tradição que valorizava somente a experiência do poder instituído, em uma narrativa gloriosa e factual, a escrita da história passou a interessar-se por experiências reais, vividas por homens e mulheres comuns. Tal interesse implicou o aumento significativo de objetos, abordagens e problemas à pesquisa em História, bem como a ampliação do ofício do historiador, sobretudo a partir do diálogo cada vez mais freqüente com outros campos do conhecimento.
Questões anteriormente relegadas, ao serem trazidas para os estudos históricos, redimensionaram interpretações existentes sobre o passado. Desse movimento emerge a história das crianças, das doenças, das mulheres, do corpo, da sexualidade, da loucura, temáticas inicialmente identificadas como história das mentalidades ou das idéias por adotarem conceitos trazidos da Antropologia, Sociologia e Psicologia. A renovação historiográfica decorrente é atribuída a Ècole des Annales, movimento que reuniu historiadores franceses com os mesmos propósitos, marcar posicionamento contrário à escrita da história tradicional (Burke P, 1991).

Um dos temas que emergiram do movimento de renovação da escrita da história tem especial identificação com a história da enfermagem: a história das mulheres. A pesquisa em história no Brasil muito recentemente incorporou a produção historiográfica que trata ações e acontecimentos praticados por mulheres. Contar a história das mulheres ou suas experiências contribuiu para retirá-las da penumbra (na qual foram duramente colocadas) e favoreceu, significativamente, para a cisão de uma historiografia estanque e esquemática, narrada a partir de sucessões de fatos e acontecimentos realizados por personagens ilustres (sempre homens).

Narrada de forma unilateral, a historiografia tradicional pouco mencionava os enredos femininos. O positivismo que norteou a escrita da história, até seguramente a passagem para o século XX, relegava experiências de mulheres ao um plano inferior, avaliando suas ações como menores em relação aos fatos que deveriam ser perpetuados, pois ainda que existissem as mulheres não eram protagonistas.

Deste modo, é possível afirmar que a escrita da história tradicional impôs uma visibilidade restritiva à participação da mulher no processo histórico, algo similar ao padrão de comportamento que as classificavam como dóceis, abnegadas, submissas, frágeis, voltadas para a manutenção da ordem familiar, exclusivamente.

Neste processo, métodos e técnicas de investigação, utilizados por outros campos do conhecimento foram incorporados ao ofício do historiador. A nova produção do conhecimento histórico e a pluralidade de abordagens sugeridas possibilitaram 
a efetiva prática interdisciplinar, na medida em que os novos problemas e a ampliação das fontes documentais minimizaram limites, aproximando o historiador de outras ciências e vice-versa. O diálogo entre campos e saberes vizinhos revelou a mais absoluta transformação da produção do conhecimento. Mitos foram derrubados e preconceitos destituídos, ou seja, a interdisciplinaridade redimensionou a noção que se tinha da práxis.

Essa trajetória tem marcado os estudos históricos. O reconhecimento da importância do passado como possibilidade de retomada de percursos interrompidos ou como possibilidade de avaliação de caminhos percorridos, têm revelado de forma contundente seus impactos em diferentes áreas do conhecimento. A Enfermagem, de forma exemplar, aponta para essa perspectiva, ao desenvolver e apoiar investigações que analisam o passado da enfermagem, da profissionalização e de seu contingente (Carnegie ME. 1995, Oguisso T. 2007, Moreira A, Oguisso T. 2005).

Ainda que pouco explorada, a pesquisa em história da enfermagem, no Brasil, tem revelado uma consciência crítica no que se refere à elaboração de novas formas de percepção e apreciação da realidade (Passos ES.1996, Mott ML.1998, Silva MF. 1995, Cyetrynowicz RA. 2000). Como salientado “...estes estudos, que nos apresentam 'o olhar do outro’ sobre nós, se por vezes nos dá uma sensação de estranhamento, são muito instigantes e a eles devemos conceder a melhor atenção, no sentido de voltarmos a considerar nossas visões e posições sobre a história da enfermagem..." (Barreira IA, Baptista SS. 2000).

\section{MULHERES NEGRAS: ENTRE PRÁTICAS E REPRESENTAÇÕES}

A perspectiva apontada permite supor que, se as mulheres foram excluídas da história, as mulheres negras foram duplamente segregadas (Perrot M. 1988). A condição feminina aliada ao traço negro afro-descendente desqualificava ainda mais a participação da mulher negra na história do Brasil, sempre representada como escrava, praticante do sexo venal, doméstica, depreciada em seus padrões de beleza, moral e comportamento (Santos GA. 2004).
Avaliar o processo de exclusão/inclusão de mulheres negras na enfermagem profissional, bem como a resistência das mulheres negras frente aos juízos intolerantes e fabricações discursivas que as desqualificavam, torna-se fundamental para o estudo da formação da identidade profissional da enfermagem brasileira. A população brasileira, durante quatro dos cinco séculos de história oficial, foi majoritariamente negra, fator que levou à constituição de uma nação miscigenada e plural do ponto de vista étnico.

De acordo com os estudos históricos, é possível afirmar que a reflexão acerca das representações e da exclusão de mulheres negras (não apenas da enfermagem moderna, mas da vida social mais ampla) encontra suas origens na história da saúde e da medicina, cuja produção revela que doenças e doentes eram definidos a partir da tradição fundada no evolucionismo e darwinismo-social. Tal perspectiva supunha que homens e mulheres negros eram sinônimo de perigo, contágio de doenças ou mais efetivamente transmissores delas (Chalhoub S. 1990, Vasconcellos MPC. 1995). Cientificamente difundidas e aceitas, as representações pautadas no bio-poder preconizavam que negros seriam naturalmente viciosos e indolentes, portanto, indisciplinados, ignorantes, incapazes de alcançar os progressos requeridos à manutenção da ordem econômica e social (Moura C. 1984).

Presos a uma força biológica que os subjugava, imprimindo-lhes inclusive o caráter, os negros estavam hereditariamente condenados, uma vez que a questão racial, nas origens da enfermagem profissional brasileira, era assumida como determinante na vida de uma pessoa. Assim avaliada, a herança genética ou a mistura das raças corromperia os sujeitos desviando-os da normalidade aparente, explicitada pela cor da pele e outros traços anatômicos (Costa JF. 1999, Souza Campos PF. 2003).

É possível afirmar que o paradigma darwinistasocial, que fundamentou ações políticas na Primeira República (1889-1930), reiterava discursos normativos que afirmavam ser a população afro-descendente naturalmente degenerada, fator que os projetava como tipos desviantes, anormais. Tal princípio era usado como critérios de definição social de uma pessoa, capaz de incluí-la ou seu 
contrário. Ou seja, as normas impostas pelo biopoder (que atingiam habitação, higiene, alimentação, sexualidade, religião e literatura) produziam juízos de valor que restringiam possibilidades de convívio social mais amplo e incitavam tensões permanentes.

Como degenerados ou criminosos natos, negros não poderiam ou não deveriam participar da esfera social mais ampla, na medida em que a contaminaria o tecido social, como alegavam discursos produtores de verdades oriundos da medicina e do direito penal (Souza Campos PF. 2003).

Nas origens da sociedade republicana, quando não assumidos como "crias da casa", os negros eram representados como páreas, dado à cristalização de imagens que os associavam a classes sociais perigosas, marcando profundamente as relações sociais no Brasil nas décadas iniciais da República (Houfbauer A. 1999).

\section{"NEM LADIES, NEM NURSES": MULHE- RES NEGRAS E ENFERMAGEM}

As visibilidades decorrentes do processo de profissionalização do cuidado formalizam a investigação em torno dos modos de exclusão racial e de gênero no ofício da enfermagem, durante a primeira metade do século XX. Reconhecida oficialmente no Brasil em 1923, em plena instauração da nova ordem social republicana, a história da enfermagem torna-se particularmente interessante para a história das mulheres negras.

Como sinalizado, em sua origem profissional, os cursos de formação deveriam evitar a presença negra (assim como a presença masculina) nos quadros discentes. Tal impedimento encontrava suporte no modelo educacional assumido como padrão profissional no Brasil, cujas origens evocam Florence Nigthingale (1820-1910) como sua precursora*. No caso brasileiro, o modelo nursing impôs critérios filtrados por enfermeiras norteamericanas que implantaram o modelo no Brasil nos primeiros anos da década de 1920 (Barreira I A. 1997).
As evidências permitem indicar que as intenções de elevar o status do cuidado, anteriormente caracterizada como prática desqualificadora, exercida por mulheres pobres e desviantes, contribuiu para o impedimento da admissão de mulheres negras na enfermagem moderna brasileira, invariavelmente representadas como desregradas, mal formadas, fora dos padrões construídos para a enfermagem e sua principal personagem: a enfermeira.

Contrariando a concepção de democracia que fundou o regime republicano no Brasil, para ingressar na profissão, era preciso ser mulher, branca, ter vocação para a arte do cuidado, possuir formação educacional e religiosa preferencialmente cristã; pré-requisitos que restringiam possibilidades de seleção e aumentavam as distâncias entre negros e brancos, pois agia na esfera cultural das práticas sociais.

A documentação que registra a história da enfermagem no Brasil revela episódios originais que permitem analisar historicamente as relações interétnicas no âmbito da enfermagem. Um desses episódios, vividos por dirigentes e alunas da Escola de Enfermeiras do Departamento Nacional de Saúde Pública, fundada em 1923, na cidade do Rio de Janeiro, desvela o problema:

É verdade que a política de organização da escola tinha sido evitar, diplomática e estrategicamente, a admissão de negros, até que a opinião pública em relação à profissão de enfermagem tivesse mudado. Isto era fundamental se pretendia atrair mulheres de melhor classe... mesmo a Academia Naval colocava obstáculos para impedir a admissão de candidatos negros. Todas as vezes em que moças de cor se candidatavam para entrar na escola, havia sempre outras boas razões para que elas não fossem qualificadas, por isso nenhum problema havia surgido até então. Na verdade, havia já na escola três estudantes que, apesar de brancas, mostravam alguns traços de sangue negro. Foi enviada uma carta à imprensa comunicando que nenhuma pretendente havia sido

\footnotetext{
* Florence Nigthingale é considerada a pioneira da Enfermagem Moderna por fundar, após a experiência da Guerra da Criméia (18531856), a Nightingale Training School for Nurses at St. Thomas Hospital, primeira escola profissional de enfermagem, em Londres, multiplicando seu modelo de ensino pelo mundo, tal como ocorreu no Brasil no início do século XX com a Reforma Carlos Chagas (3 - 22).
} 
rejeitada por causa da cor, mas não foi convincente, e o Departamento de Saúde achou que seria aconselhável permitir o ingresso de uma moça negra, se acaso se apresentasse alguma que preenchesse todos os requisitos para a admissão. Esta candidata apareceu em março, juntamente com as demais pretendentes sob forte suspeita de que havia sido mandada por um dos jornais, e foi admitida. Isto provocou uma enxurrada de protestos por parte da alunas, mas, após considerar a questão, o Conselho de Estudantes finalmente decidiu que qualquer manifestação de rejeição ou de descortesia para com uma colega de classe demonstraria falta de respeito e de vontade de cooperar, e assim não houve mais dificuldades. As estudantes deixaram claro, contudo, que esperavam que não fosse admitida nenhuma outra negra por algum tempo (Moreira MCN. 1998).

O documento revela que a admissão de uma negra e outras “...que apesar de brancas, mostravam alguns traços de sangue negro...", no interior dos quadros acadêmicos da referida escola, ao mesmo tempo que revela a discriminação racial, derruba a tese da ignorância e degeneração que as caracterizavam, motivos pelos quais eram naturalmente impossibilitadas de ingressar nos cursos profissionalizantes, como supunha a imensa maioria dos homens e mulheres brancos.

$\mathrm{O}$ registro comprova que, independentemente da origem étnica ou condição social, mulheres negras poderiam preencher os pré-requisitos exigidos a uma enfermeira, ainda que estas existissem. Estudos recentes indicam que entre as diplomadas pela Seção Feminina da Escola Profissional de Enfermeiras Alfredo Pinto, na cidade do Rio de Janeiro, no ano de 1923, havia uma mulher negra. Para além de sua localização no quadro de diplomadas (canto inferior direito), sua presença re-afirma imperativos raciais estabelecidos à construção simbólica e oficial da identidade profissional da enfermagem brasileira, o que permite trazer o debate para o campo das representações (Chartier R. 1991).

As evidências que os registros históricos evocam deslindam, por outro lado, a resistência de mulheres negras na conquista de seu espaço social, intelectual e profissional. Seus significados implicam repensar as bases que forjaram a identidade profissional da enfermagem brasileira ou então, qual seria o motivo para a exclusão das mulheres negras da formação profissional considerada oficial?

A documentação permite observar que o desejo expresso pelas alunas da Escola de Enfermagem do Departamento Nacional de Saúde Pública em não ver o episódio repetido, consubstancia a historiografia recente, quando esta afirma que a sociedade brasileira sempre rejeitou o convívio com aqueles que foram seus cativos, o que justifica a natureza das restrições impostas (Domingues PJ. 2000).

Analisada pelas lentes da cultura dos cuidados (Gonzáles JS. 1999). durante todo o processo histórico do Brasil, era intensa a participação de mulheres negras como parteiras, amas de leite, negras domésticas, babás, mães pretas, isto é, mulheres que cuidavam de enfermos, velhos e crianças, mesmo que para o cuidado das crianças muitas devessem abandonar os seus próprios filhos (Deiab RA. 2005). As relações de interdependência entre as práticas do cuidado e as populações negras no Brasil são muito próximas, porém, pouco estudadas.

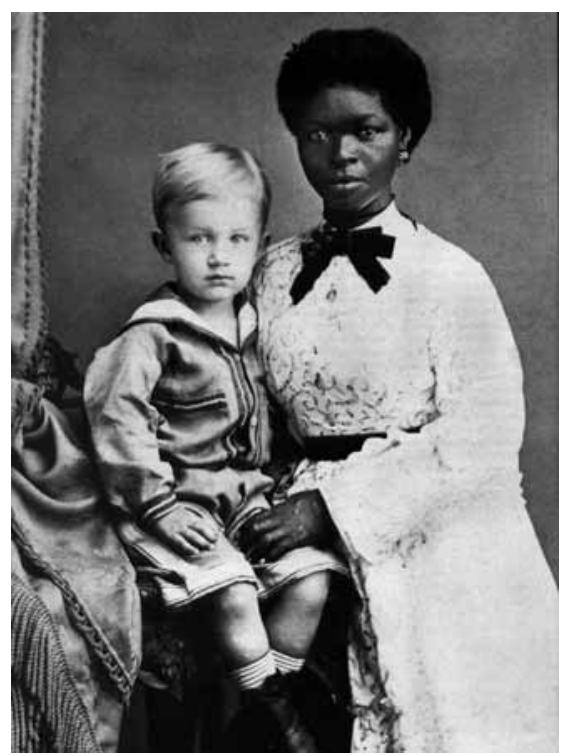

Fotografia 1: Babá com menino Eugen Keller (1874) Fonte: Alberto Henschel. Coleção George Ermakoff. Acervo Biblioteca Nacional.

A fotografia desvela o cuidado exercido por mulheres negras. A imagem fotográfica, clicada no 
atelier do alemão Albert Hanshel (primeiro grande empresário da fotografia no Brasil que em 1867 abre o escritório em Recife, seguido do escritório de Salvador, Rio de Janeiro e São Paulo) revela uma babá, mulher que cuida de crianças, quase sempre uma ama-de-leite, retratada no estado de Pernambuco, nordeste brasileiro, no ano de 1874.

A fotografia remonta o que poderia ser considerada uma cena da vida social do negro no país. Contudo, a produção da fotografia em estúdio, a vestimenta, as jóias e os adornos podem ser identificados como estratégias usadas para "embranquecer" a imagem das cuidadoras negras do Brasil. O cenário elegantemente composto indica tanto a posição assumida pelos familiares da criança no âmbito social (poder político e econômico), quanto à condição da mulher negra no Brasil (cuidadora e escrava).

No período, a imagem do Brasil deveria reiterar o cosmopolitismo europeu, a civilidade nos trópicos, pois fotografias de escritórios eram usadas como cartões postais, enviados a familiares e amigos próximos, inclusive, para manutenção do poder e status social. As fotografias fabricavam imagens, construíam consciências e veiculavam juízos formadores de opinião acerca do belo, bom, saudável, ideal.

Deste modo, torna-se factível supor que as construções discursivas, imagéticas e estéticas, que atuam no campo das mentalidades (formação das opiniões e das consciências) operaram decisivamente no processo de fabricação da identidade profissional da enfermagem brasileira. Pensado no âmbito das relações sociais, o estudo das representações permite desvelar práticas e memórias coletivas (quase sempre relegadas como objeto de estudo e investigação dos pesquisadores em história da enfermagem) que avaliam o passado a partir da profissionalização do cuidado e do modelo adotado como padrão ao ensino importado dos Estados Unidos, introduzido no Brasil pela Missão Parsons (1922). (Miranda CML.1986, Sauthier J, Barreira IA. 1999).

No caso da história da enfermagem profissional brasileira, a presença negra favoreceria a permanência de uma memória inglória, pautada em representações transformadas em correlatos de verdade. Assumido como cabais, os discursos que reiteravam a degenerescência das populações afrodescendentes, contribuíram para que o grande modelo à profissionalização da enfermagem no Brasil evitasse, reprovando, candidatas negras.

Nestes termos, o intrincado processo de apropriação dos bens culturais, de espoliação das culturas afro-descendentes, marginalizou as mulheres negras no seu próprio mundo. Analisar o processo histórico de exclusão/inclusão das mulheres negras na enfermagem profissional implica necessariamente reavaliar o estatuto atual da identidade profissional da enfermagem brasileira. Recuperadas pela memória histórico-antropológica da enfermagem, suas ações e práticas culturais são, ainda, avaliadas como pouco significativas.

Tais afirmativas tornam-se factíveis à medida que a noção de representação revela não apenas "tradução de divisão estáticas e imóveis, mas efeito de processos dinâmicos", existentes no cotidiano profissional e social (Moreira MCN. 1998). Refletir sobre as representações (do negro, da enfermagem) implica considerar que estas foram erigidas e formalizadas por discursos não neutros. Porém, sua decodificação autoriza percepções inéditas, que redimensionam o passado da cuidado no Brasil, portando, sua própria história.

\section{CONCLUSÃO}

As representações construídas às mulheres negras, que as impediram de ingressar na "enfermagem padrão", oficialmente instituída no Brasil, não foram erigidas aleatoriamente, ao contrário, fizeram parte de um intrincado processo políticoinstitucional que visava manter distância classes sociais e etnias consideradas inferiores dos quadros dirigentes da Enfermagem na Primeira República (1889-1930).

Do mesmo modo, a análise implica considerar o resultado das projeções imagético-discursivas, cristalizou a história da enfermagem como produto da profissionalização. Movimentos anteriores, cujo ensino não refletisse o padrão proposto como oficial, foram relegados pela historiografia dominante e postos à margem da história da enfermagem brasileira. A escrita da história da enfermagem, fundada na representação dominante, fabricou imagens invertidas acerca do cuidado realizado no Brasil no período imediatamente anterior à profis- 
sionalização da enfermagem brasileira, desautorizando o trabalho de mulheres negras.

As vicissitudes desse processo erigiram representações que não correspondiam com a realidade (as enfermeiras negras existiam), porém, se coadunava ao projeto político social republicano que visava branquear a sociedade. Evitar a profissionalização de mulheres negras na enfermagem oficial brasileira pode ser considerado como uma das estratégias de dominação e controle das populações afro-descendentes, aqui retratadas pelas cuidadoras negras do Brasil.

\section{REFERÊNCIAS}

- Barreira IA, Baptista SS. (2000) A Pesquisa e Documentação em História da Enfermagem no Brasil, Rev. Enf. Esc. Anna Nery. 4(3): 396-403.

- Barreira I A. (1997) Os Primórdios da Enfermagem Moderna no Brasil. Esc. Anna Nery - Revi. Enferm. 1(número de lançamento); 161-76.

- Burke P. (1991) A Escola dos Annales. A Revolução Francesa da Historiografia. São Paulo: Edunesp.

Carnegie ME. (1995)The Path we Tread. Blacks in Nursing Worldwide, 1854-1994. 3a ed. New York: National League for Nursing Press.

Costa JF. (1999) Ordem médica e norma familiar. 4a ed. Rio de Janeiro: Graal.

Cyetrynowicz RA. (2000) Serviço da Pátria: mobilização das enfermeiras no Brasil durante a Segunda Guerra. História, Ciências, Saúde: Manguinhos. 3(1):73-91.

- Chalhoub S.(1990) Classes pobres, classes perigosas. Trabalhadores. 6(1);2-22.

Chartier R. (1991) O Mundo como Representação. Estudos Avançados 5(11):173-91.

Deiab RA.(2005) A Memória afetiva da escravidão. Rev História da Biblioteca Nacional, (1) 4:36-40.

- Domingues PJ. (2000) Uma História mal Contada. Negro, racismo e trabalho no pós-abolição em São Paulo (19891930). [dissertação]. São Paulo: Faculdade de Filosofia, Letras e Ciências Humanas da USP.

Gonzáles JS.(1999) Historia de la Enfermeria. Alicante: Aguaclara.

- Houfbauer A. (1999) Uma história do branqueamento ou o negro em questão. [tese]. São Paulo: Faculdade de Filosofia, Letras e Ciências Humanas da USP.

- Miranda CML.(1986) O Risco e o bordado. Um estudo sobre formação de identidade profissional. Rio de Janeiro: EEAN/UFRJ.

- Moreira MCN. (1998) A Fundação Rockefeller e a construção da identidade profissional de enfermagem n Brasil na Primeira República. História, Ciências, Saúde - Manguinhos; 3(1): 621-45.

- Moreira A, Oguisso T. (2005) Profissionalização da Enfermagem Brasileira. Rio de Janeiro: Guanabara Koogan.

Mott ML.(1998) Parto, parteiras e parturientes no século XIX. [tese]. São Paulo: Faculdade de Filosofia, Letras e Ciências Humanas da USP.
- Moura C. (1984) As Injustiças de Clio. O negro na historiografia brasileira. São Paulo: Nossa Terra.

- Oguisso T. (2007) Trajetória Histórica e Legal da Enfermagem. Barueri: Manole.

- Passos ES.(1996) De anjos a mulheres: ideologias e valores na formação de enfermeiras. Salvador :EDUFBA;EGBA.

- Perrot M. (1988) Os excluídos da história: homens, mulheres, prisioneiros. Rio de Janeiro: Paz e Terra.

- Santos GA. (2004) Mulher negra, homem branco. Rio de Janeiro: Pallas.

- Sauthier J, Barreira IA. (1999) As enfermeiras norte-americanas e o ensino da enfermagem na capital do Brasil: 19211931. Rio de Janeiro: Editora Ana Nery.

- Silva MF. (1995) Resgatando a Memória: a História das Enfermeiras da Força Expedicionária Brasileira na II Guerra Mundial. [dissertação] Rio de Janeiro: Escola de Enfermagem Anna Nery daUFRJ.

- Souza Campos PF. (2003) Os crimes de preto Amaral. Representações da degenerescência em São Paulo. 1920. [tese]. Assis: Faculdade de Ciências e Letras da UNESP.

- Vasconcellos MPC. (1995) Memórias da Saúde Pública. A fotografia como testemunha. São Paulo: Hucitec/Abrasco.

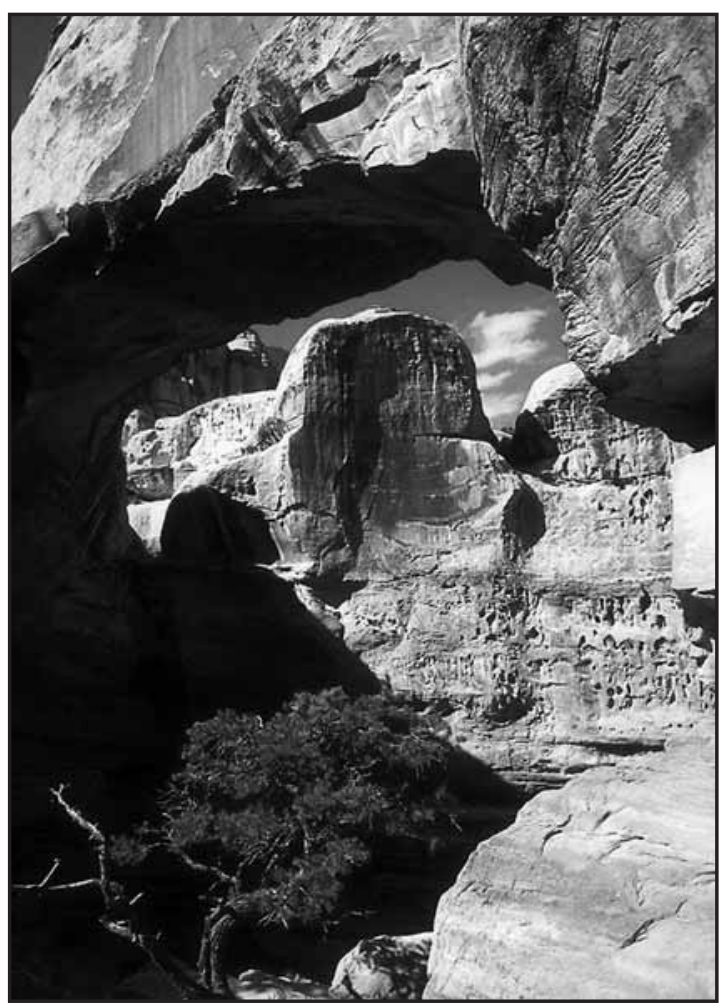

